http://dx.doi.org/10.4314/ajtcam.v11i6.9

\title{
EVALUATION OF THE EFFECT OF SPATHODEA CAMPANULATA FLOWER BUD EXUDATE ON CATARACTOGENESIS IN RAT LENSES
}

\author{
Adio Gbemisola I. ${ }^{1}$, Faluyi J. O. ${ }^{2}$ and Osoniyi O. ${ }^{1}$ \\ ${ }^{1}$ Department of Biochemistry, ${ }^{2}$ Department of Botany, Obafemi Awolowo University, Ile-Ife \\ E-mail: rosoniyi@oauife.edu.ng
}

\begin{abstract}
Background: The flower bud exudates of Spathodea campanulata is commonly used as a local eye drop in Nigeria and is anecdotally claimed to improve vision. This study evaluated the anti-cataract activity of Spathodea campanulata (SPCM) flower bud exudates against cataractogenesis using rat lenses. This was done with a view to providing empirical scientific support for the use of the exudates from SPCM in the treatment and management of certain eye disorders.

Materials and Methods: Fifty (50) rat lenses were used in this study, i.e. five groups of ten (10) lenses per group. Lenses were incubated in artificial aqueous humor (Normal control) with simultaneous incubation in $30 \mathrm{mM}$ galactose (Untreated cataract). Co-incubation with captopril (Captopril treated cataract); $0.1 \mathrm{mg} / \mathrm{ml}$ of the exudate (Exudate treated cataract - Low dose) and $0.2 \mathrm{mg} / \mathrm{ml}$ of exudate (Exudate treated cataract- High dose) constituted the study groups. After $72 \mathrm{hr}$ of incubation, lenses were observed for cataract and the preventive potential of the exudate against cataractogenesis was evaluated through the determination of the levels of anti-oxidant parameters such as total protein (TP), glutathione (GSH), malondialdehyde (MDA) and activities of superoxide dismutase (SOD) and catalase (CAT) were evaluated in the lens homogenates.

Results: Photographic evaluation of the lenses showed the development of cataract in the untreated cataract group while opacification was retarded in higher dose exudate-treated and captopril treated lenses. Significant decrease in the levels of GSH and total protein, reduction in SOD and CAT activities as well as increase in MDA content were observed in cataractous lenses when compared with the normal control. SPCM displayed a doserelated anti-cataract activity. Captopril showed comparable anti-cataract potential to $(0.2 \mathrm{mg} / \mathrm{ml})$ SPCM. GSH, SOD and CAT activity in captopril treated cataract lenses increased to $75.55 \%, 64.08 \%$ and $72.45 \%$ of the normal control values respectively. In $(0.2 \mathrm{mg} / \mathrm{ml}) \mathrm{exudate}$ treated cataract lenses; GSH, SOD and CAT activity increased to $57.7 \%, 76.69 \%$ and $80.61 \%$ respectively.
\end{abstract}

Conclusion: The study concluded that exudate of SPCM elicited its anti-cataract potential through its anti-oxidant activities.

Key words: Eye, Cataract, Spathodea campanulata

\section{Introduction}

Cataract is a major cause of blindness in the world (Shichi, 2004). It is estimated that about $41.8 \%$ of blindness in the world is caused by cataract with a higher incidence in developing countries (Shakil et al., 2008).

Cataract is characterized by opacification and breakdown of the micro-architecture in the crystalline eye lens which interferes with the transmission of light onto the retina (Umamaheswari et al., 2012), causing blurriness of near image vision, abnormal color perception, diplopia, impaired vision acuity (Head, 2001) and hence vision deterioration (Pintor, 2012b).

The target tissue of opacification is the lens which is an avascular tissue having three layers; the outer capsule, the middle cortex and the inner nuclear layer. Based on this, cataractogenesis is of three main types; the nuclear cataract, the cortical cataract and the posterior sub-capsular cataract (Patel et al., 2012). In any of these types, the etiology of cataract is diverse and there is difficulty attributing its cause exclusively to a single factor (Pintor, 2012a). However, risk factors such as socio-economic/educational level, metabolic disorders like diabetes, long-term use of steroids (Jobling and Augusteyn, 2002; Shakil et al., 2008), smoking (Eman and Elabrak, 2011), nutrition, excessive exposure to sunlight (Zarina et al., 1994) and aging (Kisic et al., 2012) may play a role. Moreover, studies over the years have established oxidative stress as a major factor that triggers cataractogenesis (Williams, 2006; Babizhaye et al., 2010) with lipid peroxidation products in the lens correlating with opacity (Marsili et al., 2004). Lipid peroxidation may be triggered by endogenous and exogenous insults such as reactive oxygen species (ROS), metal ions, ultraviolet irradiations and drugs (Kisic et al., 2012). Peroxidation of biomolecules such as the lens membrane lipids and proteins compromise the structure and functions of these molecules leading to increased permeability and change in the lens micro-environment (Kisic et al., 2012). Due to osmotic imbalance, the lens becomes hydrated (Kinoshita, 1974) resulting in refractive index fluctuation, electrolyte imbalance (Kisic et al., 2012) and oxidation and precipitation of proteins (Head, 2001).

Under hyperglycemic conditions, proteins undergo glycation (Kyselova et al., 2004; Patel, 2012). Ocular tissues however contain antioxidants (enzymatic and non-enzymatic) that prevent oxidative damages (Kisic et al., 2012) but when these barriers are broken, cataract develops. The only treatment available is the surgical removal of the lens with artificial replacement as there is no other effective means of treatment (Zarina et al., 1994). Even drugs that were developed to delay or prevent opacification have failed to give convincing results when tested (Marsili et al., 2004). Although cataract surgery is highly effective, the limited number of surgeons especially in developing countries is a major limitation (Kyselova et al., 2004).

Again, the high cost of surgery coupled with complications such as bleeding (hyphema), lens capsule rupture, loss of the vitreous humor, iris detachment and opacification of the posterior capsule afterwards have made surgery non-efficient (Marcantonio and Vrensen, 1999). There is therefore a need to explore non-surgical interventions.

Spathodea campanulata, also known as the African tulip tree, fountain tree or the flame of the forest is widely used as an ornamental plant (Trigo and Santos, 1998; Zaheer et al., 2011). The extracts of leaves, stem bark, flower and roots are used in ethno-medicine for the treatment of various diseases 
(Ofori-kwakye, 2011). The exudate from the flower bud is applied to the eye and has been claimed to improve vision and prevent eye diseases. There is however no empirical scientific study to back up these claims, as a result this study.

\section{Materials and Methods Reagents and Chemicals}

The reference drug, captopril, was procured from a Registered Pharmacy in Ile-Ife. Other reagents and chemicals used including 5,5'-dithiobis-nitrobenzenzoic acid, adrenalin, reduced glutathione, Bovine serum albumin, ascorbic acid, quercetin, gallic acid, 2,2-diphenyl-2-picrylhydrazyl hydrate (DPPH), ferric chloride, 2, 4, 6-tri-(2-pyridyl)-1, 3, 5-triazine (TPTZ), ammonium molybdate and hydrogen peroxide were of analytical grade obtained either from Sigma Aldrich, St. Louis, USA or British Drug House (BDH) Limited, Poole, England

\section{Plant Material}

Fresh flower buds of Spathodea campanulata were collected from a tulip tree at Obafemi Awolowo University, Ile-Ife, Osun State, Nigeria. The plant was identified at IFE Herbarium with the voucher number (17227). The buds exudate was collected by cutting off the tip of the bud and pressing to release the exudate into a brown bottle. It was then kept at $4^{\circ} \mathrm{C}$ prior to use.

\section{Experimental Animals}

Healthy White Albino rats (25) of either sex (80-110kg) were purchased from the animal holding facility of the college of Health Sciences, Obafemi Awolowo University, Ile-Ife, Nigeria. The animals were acclimatized for one week and fed with standard rat chow (purchased from Ladokun Feeds, Ibadan, Nigeria) and water ad libitum.

\section{Collection of Eye Balls of Rats}

Animals were euthanized under light chloroform anesthesia with the eyeballs removed from the eye socket by dissection. The lenses were carefully removed using posterior approach to prevent damage to the lens capsules.

\section{Culturing of Lens and Cataract Induction}

The lenses were incubated in artificial aqueous humor $\left(140 \mathrm{mM} \mathrm{NaCl}, 5 \mathrm{mM} \mathrm{KCl}, 2 \mathrm{mM} \mathrm{MgCl}_{2}, 0.5 \mathrm{mM} \mathrm{NaHCO}_{3}, 0.5 \mathrm{mM} \mathrm{Na}_{2} \mathrm{HPO}_{4}, 0.4 \mathrm{mM}^{2}\right.$ $\mathrm{CaCl}_{2}$, and $5 \mathrm{mM}$ Glucose, $\mathrm{pH}$ of 7.8) for 72 hours in an incubating chamber at room temperature. Added to the artificial aqueous humor were 100 $\mu \mathrm{g} / \mathrm{ml}$ of streptomycin and $100 \mathrm{IU} / \mathrm{ml}$ of penicillin to prevent bacterial contamination. All culturing equipments were made sterile with the culturing media autoclaved and changed every $24 \mathrm{~h}$ throughout the incubation period. Galactose (30 mM) served as cataract inducer (Malone et al., 1993).

\section{Study Groups}

Eye lenses were randomly sorted into 5 groups of 10 lenses each and treated as follows:

Group 1: Lens + Artificial aqueous humor (AAH) (Normal Control- NC)

Group 2: Lens + AAH + $30 \mathrm{mM}$ Galactose (Untreated Cataract- UC)

Group 3: Lens + AAH + $30 \mathrm{mM}$ Galactose $+5 \mathrm{mM}$ Captopril (Captopril treated cataract- CC)

Group 4: Lens + AAH + $30 \mathrm{mM}$ Galactose $+0.1 \mathrm{mg} / \mathrm{ml}$ exudate (Exudate treated cataract- Low Dose- LD)

Group 5: Lens + AAH + $30 \mathrm{mM}$ Galactose $+0.2 \mathrm{mg} / \mathrm{ml}$ exudate (Exudate treated cataract-High

Dose- HD)

* Captopril is a synthetic 3-mercapto-2-methylpropionyl derivative of L-proline, reported to possess anticataract potential (Lakshmi et al., 2009) and is one of the most commonly used drugs in treatment of cataract.

\section{Photographic Evaluation}

After 72 hours of incubation, lenses were mounted and observed for opacity by placing the lenses on a grid. The pattern of the grid observed through the lens using a Durst enlarger at a magnification of X6.5.

\section{Preparation of Lens Homogenates}

Lenses (10) were homogenized in $10 \%(\mathrm{w} / \mathrm{v})$ of $0.1 \mathrm{M}$ potassium phosphate buffer at $\mathrm{pH}$ 7.0. The homogenate was centrifuged at 10,000 rpm (Centurion Scientific Ltd U.K; R-1880) at $4^{\circ} \mathrm{C}$ for $1 \mathrm{~h}$. The supernatants were collected and used for estimation of biochemical parameters.

\section{Phytochemical Screening and Antioxidant Analyses of the Exudate}

The flower bud exudate was subjected to phytochemical screening using standard procedure earlier described by Sofowora (1993), Trease and Evans (2002) and Nayak and Pereira (2006). 
The flavonoid content was determined using aluminium chloride reaction method of Zhilen et al. (1999) as described by Miliauskas et al. (2004) and the total phenolic content was determined using the method of Singleton and Rossi (1965) as described by Gulcin et al. (2003).

The antioxidant potentials of the exudate were evaluated using the total antioxidant activity and ferric reducing antioxidant power (FRAP) assays as described by Prieto et al. (1998), and Benzie and Strain (1999) respectively. The radical scavenging ability of the exudate was determined using the stable 2,2-diphenyl-2-picrylhydrazyl hydrate (DPPH) radical (Brand-Williams et al., 1995).

Reduced glutathione was determined by the method of Moron et al. (1979) and total protein content was determined using the Lowry method (Lowry et al., 1951). The degree of oxidative stress was assessed by measuring malondialdehyde (MDA) levels by TBARS-method (Parihar and Taruna, 2003), Superoxide dismutase (SOD) activity (Misra and Fridovich, 1972) and catalase activity (Rocha et al., 2003).

\section{Statistical Analysis}

All data were expressed as mean \pm SEM of $n=3$ readings. Difference between mean values was determined by One-way Analysis of Variance (ANOVA) followed by Tukey post-test and differences with $\mathrm{p}<0.05$ were considered significant.

\section{Results}

Phytochemical Screening of the exudate revealed the presence of alkaloids, flavonoids, saponin, cardiac glycosides and triterpenoids in trace amount while anthraquinones and tannins were not detected.

\section{Evaluation of in vitro Antioxidant Potentials of the Exudate}

The total flavonoids and total phenolic contents of the exudate were $2.80 \pm 0.16 \mathrm{mgQE} / \mathrm{g}$ of exudate $(\mathrm{QE}=$ quercetin equivalent) and $22.67 \pm 0.33 \mathrm{mgGAE} / \mathrm{g}$ of exudate (GAE= Gallic acid equivalent) respectively. The exudate and the standard antioxidant, ascorbic acid, exhibited a concentration-dependent inhibition of DPPH radical. The $\mathrm{IC}_{50}$ values for ascorbic acid and the exudate were $7.27 \mu \mathrm{g} / \mathrm{ml}$ and $61.8 \mu \mathrm{g} / \mathrm{ml} \mathrm{respectively}$. The reducing power of the exudates as indicated by the ferric Reducing Antioxidant Power assay was 23.33 $\pm 0.33 \mathrm{mgAAE} / \mathrm{g}$ of exudate (AAE= Ascorbic acid equivalent) and the total antioxidant capability was $27.333 \pm 0.67 \mathrm{mgAAE} / \mathrm{g}$ of exudate.

\section{Photographic Evaluation}

Photographic evaluation after 72 hours of incubation showed that the untreated cataract group developed opacity (Plate 1B). Compared to the normal control (Plate 1A), captopril treated cataract (Plate 1C) and $0.2 \mathrm{mg} / \mathrm{ml} \mathrm{SPCM}$ (Plate 1E) treated cataract lenses retained a comparable degree of transparency. Captopril and SPCM $(0.2 \mathrm{mg} / \mathrm{ml})$ were able to protect or retard cataractogenesis while $0.1 \mathrm{mg} / \mathrm{ml} \mathrm{SPCM}$ (Plate $1 \mathrm{D})$ showed a lower potency to protect against cataract development.

\section{Biochemical Parameters}

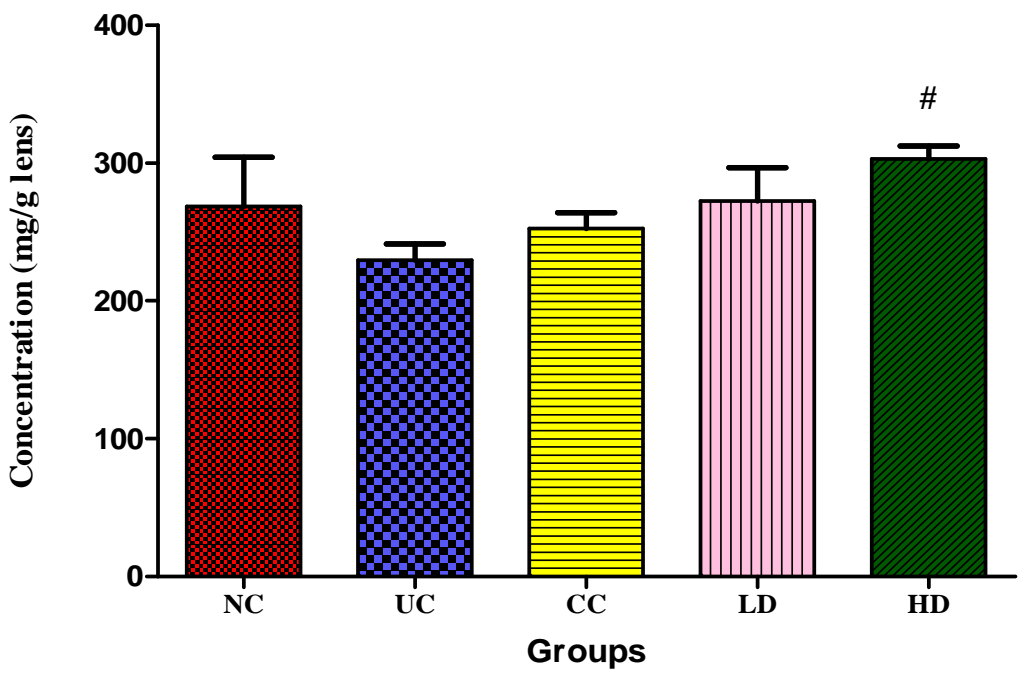

$* \mathrm{NC}=$ Normal Control; $\mathrm{UC}=$ Untreated Cataract $\mathrm{CC}=$ Captopril Treated Cataract $\mathrm{LD}=$ Exudate Treated Cataract- Low Dose; HD= Exudate Treated Cataract- High Dose

Figure 1: Concentrations of Total Protein in Normal, Untreated and Treated Rat Lenses

Values represent mean \pm SEM, $\mathrm{n}=3$ readings. ${ }^{\#} \mathrm{p}<0.05$ when compared to untreated cataract 
Figure 1 is the summary of total protein concentrations in lenses across the treatment groups. The protein concentration of the untreated cataract group decreased to $85.56 \%$ of the normal control value. Treatment with captopril increased protein concentration to $94.06 \%$ of the normal control value. SPCM exudate at the lower and higher doses increased protein concentration to $101.49 \%$ and $112.86 \%$ of normal control value respectively.

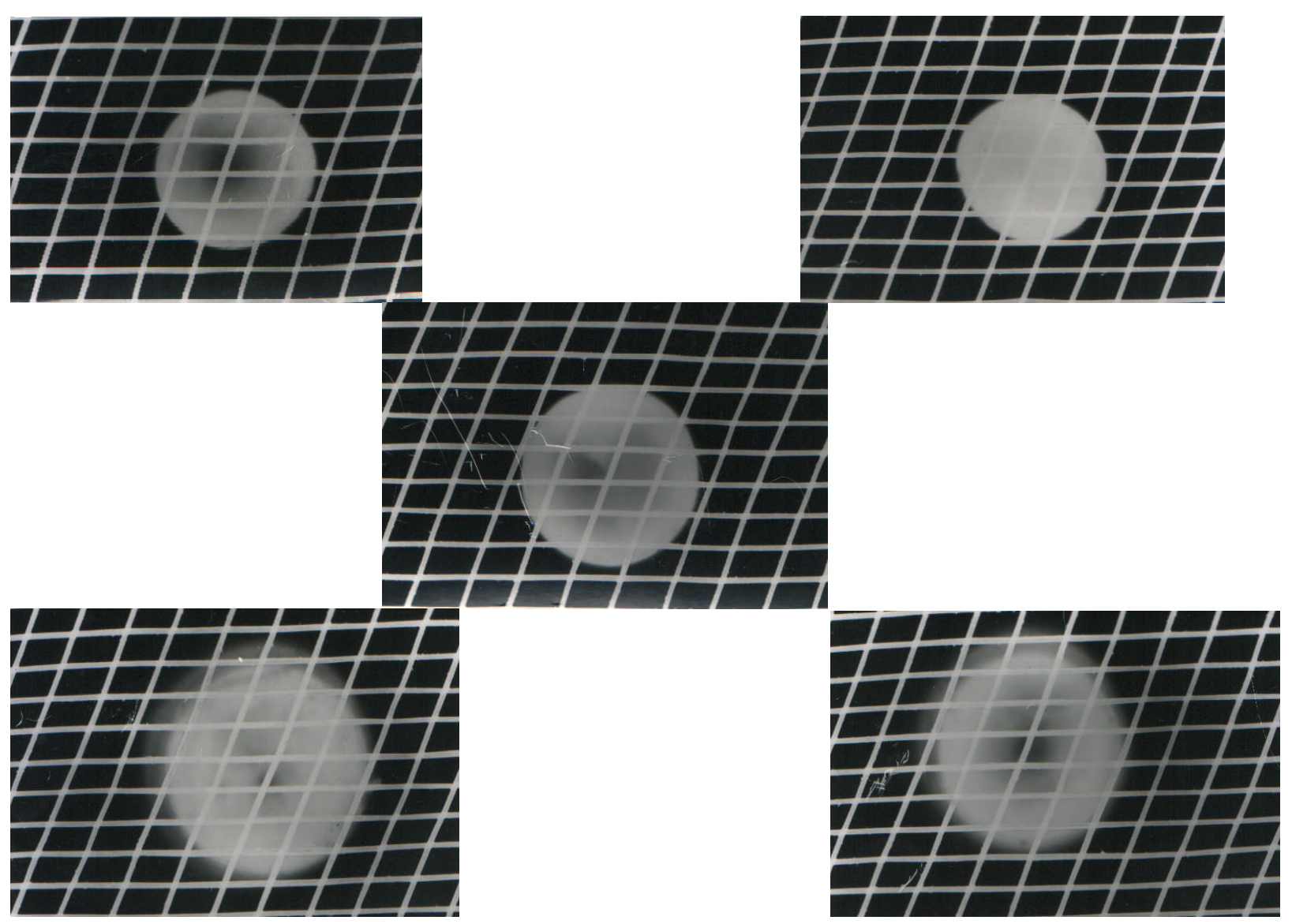

Plate 1: Representative Photographs of Normal and Treated Lenses (A)Normal control; (B) Untreated cataract; (C) Captopril treated cataract; (D) Exudate treated cataract- Low dose; (E) Exudate treated cataract- High dose.

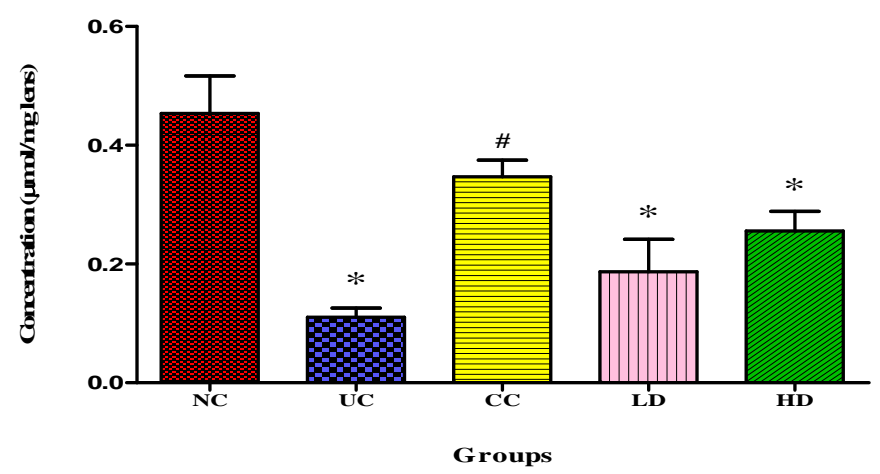

$\mathrm{NC}=$ Normal Control; $\mathrm{UC}=$ Untreated Cataract $\mathrm{CC}=$ Captopril Treated Cataract $\mathrm{LD}=$ Exudate Treated Cataract- Low Dose $\mathrm{HD}=\mathrm{Exudate}$ Treated Cataract- High Dose

Figure 2: Concentrations of Reduced Glutathione in Normal, Untreated and Treated Rat Lenses

Values represent mean \pm SEM, $n=3$ readings. ${ }^{*} \mathrm{p}<0.05$ when compared to normal control; ${ }^{*} \mathrm{p}<0.05$ when compared to untreated cataract Figure 2 is the summary of reduced glutathione concentrations in lenses of the different treatment groups. The reduced glutathione concentration dropped to $24.44 \%$ of normal control value. Captopril, SPCM at $0.2 \mathrm{mg} / \mathrm{ml}$ and $0.1 \mathrm{mg} / \mathrm{ml}$ protected the lenses and increased the reduced GSH concentration to $75.55 \%, 57.7 \%$ and $42.22 \%$ of the normal control value respectively. 


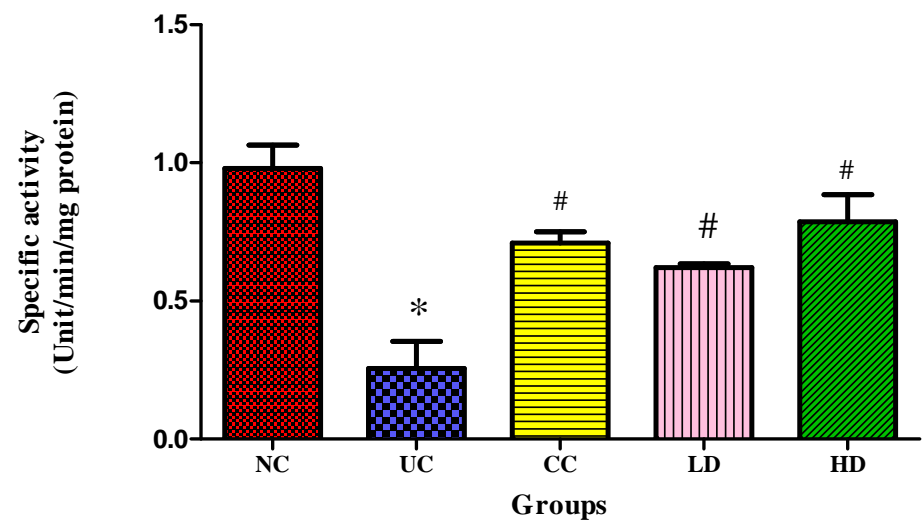

$* \mathrm{NC}=$ Normal Control; UC= Untreated Cataract; $\mathrm{CC}=$ Captopril Treated Cataract; $\mathrm{LD}=$ Exudate Treated Cataract- Low Dose; HD= Exudate Treated Cataract- High Dose

Figure 3: Catalase Activity in Normal, Untreated and Treated Rat Lenses

Values represent mean $\pm \mathrm{SEM}, \mathrm{n}=3$ readings. * $\mathrm{p}<0.05$ when compared to normal control; ${ }^{\#} \mathrm{p}<0.05$ when compared to untreated cataract

Fig. 3 is the summary of catalase activity in lenses across the different treatment groups. In untreated cataract lens, catalase activity dropped to $25.51 \%$ of the normal controls. Treatment with captopril resulted in increased activity to $72.45 \%$ of normal control value. Treatment with SPCM resulted in catalase activities of $63.27 \%$ and $80.61 \%$ of normal control value at the lower and higher doses respectively.

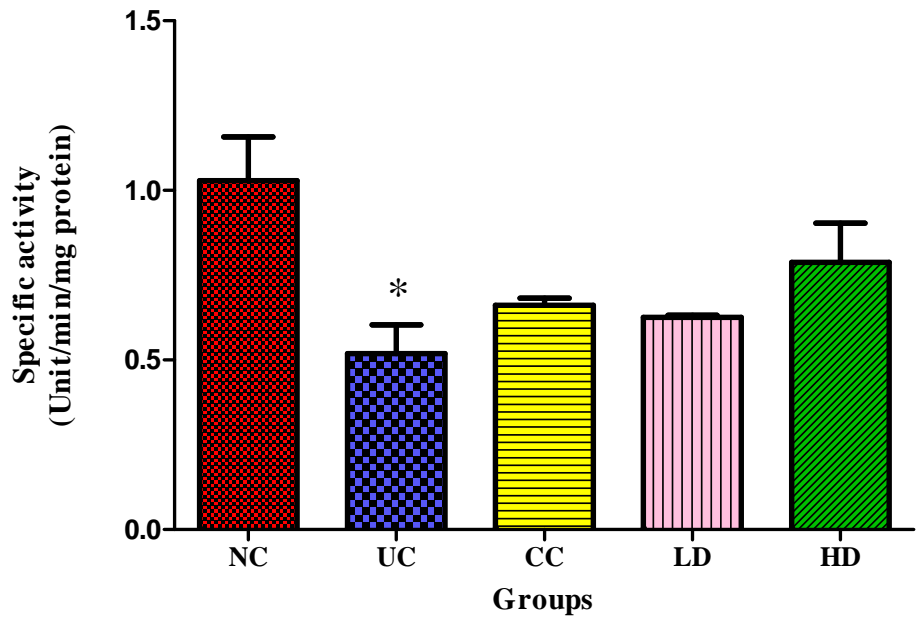

$* \mathrm{NC}=$ Normal Control; UC= Untreated Cataract $\mathrm{CC}=$ Captopril Treated Cataract $\mathrm{LD}=$ Exudate Treated Cataract- Low Dose; HD= Exudate Treated Cataract- High Dose

Figure 4: Superoxide Dismutase Activity in Normal, Untreated and Treated Rat Lenses

Values represent mean \pm SEM, $n=3$ readings. $* \mathrm{p}<0.05$ when compared to normal control

Figure 4 is the summary of superoxide dismutase activity in lenses across the different treatment groups. SOD activity of the untreated cataract lenses decreased to $50.49 \%$ of normal controls. Treatment with captopril resulted in activity of $64.08 \%$ of normal control lenses. Cataractous lenses treated with the lower and higher doses of SPCM however had activities of $61.17 \%$ and $76.69 \%$ of normal control value respectively. 


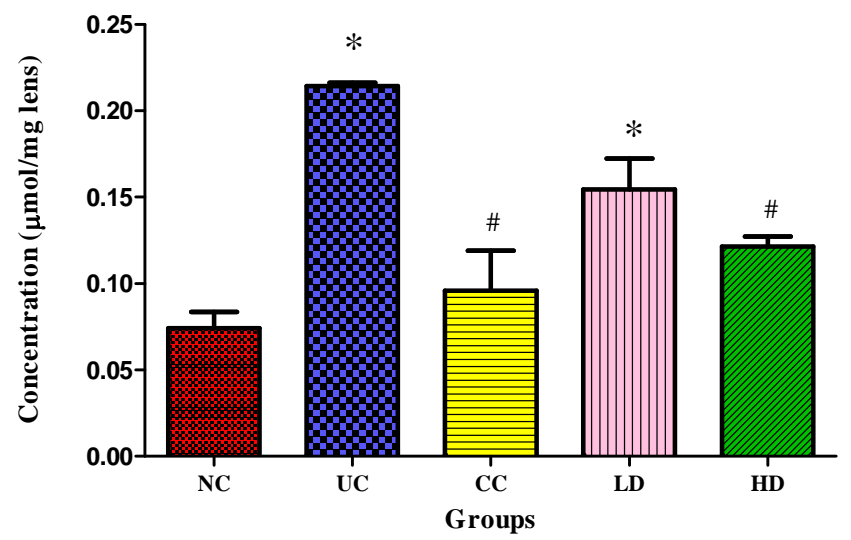

$* \mathrm{NC}=$ Normal Control; UC= Untreated Cataract $\mathrm{CC}=$ Captopril Treated Cataract $\mathrm{LD}=$ Exudate Treated Cataract- Low Dose; HD $=$ Exudate Treated Cataract- High Dose

Figure 5: Lipid Peroxidation (Malondialdehyde) in Normal, Untreated and Treated Rat Lenses

Values represent mean $\pm \mathrm{SEM}, \mathrm{n}=3$ readings. $* \mathrm{p}<0.05$ when compared to normal control; $\#$ p $<0.05$ when compared to untreated cataract.

Figure 5 is the summary of malondialdehyde concentrations in lenses across the different treatment groups. Significant increase (to $300 \%$ of the normal control value) in MDA level was seen in the untreated cataract lenses. The anti-cataract activity of Captopril and SPCM $0.2 \mathrm{mg} / \mathrm{ml}$ protected the lenses against lipid peroxidation by increasing concentration of MDA to $142.86 \%$ and $171.43 \%$ of the normal control value respectively. The increase was to $214 \%$ of the normal control value in SPCM $0.1 \mathrm{mg} / \mathrm{ml}$ treated cataract lenses.

\section{Discussion}

The sense organ for vision, the eye, is the most complex organ of the five sense organs of the human body (Segre, 2014). It is responsible for collection of light rays, focusing it on the retina and encoding the neural signal sent to the brain for interpretation (Prasad and Gelatta, 2011). For the eye to perform these functions effectively the lens has to remain transparent. However, in cataract, the crystalline eye lens is opacified leading to the loss of transparency. Among the various experimental models used in cataractogenesis studies, the sugar-induced cataract model is used in this study as it is a commonly used model that assumes that factors initiating galactose-induced cataracts in young rats are similar to those involved in the human sugar-cataract model (Kinoshita, 1965). The underlying mechanisms in sugar-induced cataract are becoming unraveled. Galactose is reduced to galactitol by the aldose reductase and causes hydration of the eye which eventually leads to osmotic stress (Patterson and Bunting, 1965; Kinoshita, 1974; Lakshmi and Sharma, 2011), thereby causing enzyme inactivation (such as $\mathrm{Na}^{+} \mathrm{K}^{-}$ATPase), loss of membrane integrity, refractive index fluctuations and loss of protein functions (Kisic et al., 2012). These effects are further aggravated by increased hydration due to high concentration of protein in the lens (Patterson and Bunting, 1965). Earlier studies have also implicated glycation of lens proteins (as measured by the protein carbonyl content as well as the concentration of glycation products) in nuclear lens protein, which was found to be higher in cataractous lens (Lyons et al., 1991, Suryanarayana et al., 2007).

Cross-linking and aggregation of proteins, considered to be a major change that results in lens opacification has been reported in sugarinduced cataract (Luthra and Balasubramania, 1993) with subsequent formation and accumulation of advanced glycation end-products which itself is a pro-oxidant (Luthra and Balasubramania, 1993; Hsu and Zimmer, 2010). This preoxidant and other free radicals generated through auto-oxidation of sugars lead to oxidative stress (Jyothi et al., 2003; Marsili et al., 2004; Gupta et al., 2009) to which the lens is highly susceptible (Sasikala et al., 2010). Previous studies established oxidative stress as a triggering factor in the development of cataract (Williams, 2006) with augmentation of the antioxidant defenses of the lens seen to prevent or delay cataractogenesis (Spector, 1995).

In this study, antioxidant property of Spathodea campanulata flower bud exudate was examined with the total phenolic and flavonoid contents quantified. This study revealed total phenolic and total flavonoid concentrations of $22.67 \mathrm{mgGAE} / \mathrm{g}$ exudate and $2.80 \mathrm{mgQE} / \mathrm{g}$ exudate respectively. Vijayasanthi and Kannan (2013) previously reported S. campanula leaves to have a total phenolic and flavonoid content of 162 $\mathrm{mgGAE} / \mathrm{g}$ dry materials and $61.23 \mathrm{mgQE} / \mathrm{g}$ dry materials respectively in the aqueous extract. However, Trigonella foenum-graecum seed previously shown to possess anti-cataract activity (Gupta et al., 2009) was seen to have a total phenolic content of $6.85 \mathrm{mgGAE} / \mathrm{g}$ of seed and a total flavonoid content $0.65 \mathrm{mgQE} / \mathrm{g}$ of seed (Bukhari et al., 2008) which is lower than that of $S$. campanulata flower bud exudate. Generally, polyphenols are widely studied for their antioxidant properties (Perron and Brumaghim, 2009) and there are quite a number of methods used for evaluating antioxidant activity of plants. Among these, 2,2-diphenyl-2-picrylhydrazyl hydrate (DPPH) scavenging assay, ferric reducing power assay and total antioxidant assay were used in this study.

DPPH is a commercially available radical which upon reduction by an anti-oxidant has its purple color fading, an outcome that is measured spectrophotometrically. DPPH scavenging assay of the exudate showed concentration dependent inhibition of DPPH radical, with the scavenging ability increasing with increasing concentration. The $\mathrm{IC}_{50}$ (concentration at which the exudate causes $50 \%$ inhibition of DPPH radical) of the exudate was found to be $64.91 \mu \mathrm{g} / \mathrm{ml}$ while the reference ascorbic acid standard had an $\mathrm{IC}_{50}$ of $7.27 \mu \mathrm{g} / \mathrm{ml}$. Since a low $\mathrm{IC}_{50}$ value indicates strong antioxidant activity (Duganath, 2010), it could be concluded that the exudate was about nine (9) times less active than ascorbic acid in transfer of hydrogen ions to oxidants. This activity is however, still remarkable, considering that a previous study measuring the DPPH radical scavenging activity of extracts of the flower of $S$. campanulata reported an $\mathrm{IC}_{50}$ value of $225 \mu \mathrm{g} / \mathrm{ml}$ (Hareesh et al., 2010). 
Determination of the flower bud exudates' ability to reduce ferric (III) iron to ferrous (II) iron and molybdenum (VI) to molybdenum (V) using ferric reducing antioxidant power (FRAP) assay and total antioxidant assay respectively were investigated. The exudate showed a concentration of $23.33 \mathrm{mg}$ ascorbic acid equivalent per gram of exudate in reducing ferric (III) iron to ferrous (II) iron and $27.33 \mathrm{mg}$ ascorbic acid equivalent per gram of exudate in reducing molybdenum (VI) to molybdenum $(\mathrm{V})$.

The exudate was screened for the presence of plant secondary metabolites. The analysis revealed absence of anthraquinones and tannins while alkaloids, flavonoids, saponin, glycosides and triterpenoids were found present. Screening of $S$. campanulata flowers and leaves showed that the flower and leaves had steroids and tannins in addition to phytochemicals present in the exudate (Hareesh et al., 2010; Ilodigwe et al., 2010; Kowti et al., 2010). Ilodigwe et al. (2010) however found anthraquinone present in the ethanolic leaf extract. Screening of the flower base fluid of $S$. campanulata was equally positive for steroids while alkaloids, tannins and triterpenoids were absent (Killedar et al., 2011). Generally, phytochemicals are biologically active compounds some of which are known to have antioxidant effect (Akinmoladun et al., 2007)

In this study, cataract was successfully induced by culturing the lenses in media containing $30 \mathrm{mM}$ galactose (Plate 1B). Captopril at a concentration of $5 \mathrm{mM}$ and $S$. campanulata at $0.2 \mathrm{mg} / \mathrm{ml}$ concentrations offered protection against cataract development or retarded the process of cataractogenesis (Plate 1C and 1E). Photographic evaluation of the low dose $(0.1 \mathrm{mg} / \mathrm{ml})$ treated cataract lens however showed a lower degree of transparency (Plate 1D) when compared to the control, captopril and the high dose treated cataract lenses. Thus, indicating a lower potency to protect against cataract development. The results of the photographic evaluation of the lenses, showing a dose related protection, are further supported by the results from the biochemical assays.

Malondialdehyde, an indicator of lipid peroxidation was found to be higher in the untreated cataract group (300\% of the normal control value) and $0.1 \mathrm{mg} / \mathrm{ml}$ SPCM-treated cataract group (214\% of the normal control value) compared to other test groups (Fig. 5). The increase might have been caused by increased lipid peroxidation. The result was similar to the observations of Jyothi et al. (1993) in a study tracking peroxidation in premature, mature and hypermature galactogenic cataract model. Increased MDA concentrations in cataractogenic models have been previously reported in in vivo and in vitro studies (Nair 2010; Umamaheswari et al., 2012). Lipid peroxidation is regarded as a pathogenic factor of cataractogenesis (Kisic et al., 2012) that could be induced by reactive oxygen species or oxygen radicals. Significant decrease in malondialdehyde concentrations of SPCM $(0.2 \mathrm{mg} / \mathrm{ml})$ and captopril $(5 \mathrm{Mm})$ treated cataract groups is an indication of protection against peroxidation with the possibility of preserved structural integrity of the lens fibre membranes.

The protein concentration of the untreated cataract group decreased to $85.56 \%$ of the normal control value (Fig. 1). Earlier, reduction to $89.26 \%$ and $81.1 \%$ of the normal control lenses in premature and mature galactose-induced cataract in vivo has been reported by Jyothi et al. (2003). The reduction might be attributed to fragmentation and subsequent leakage of proteins due to the disruption of the lens fibre membranes. Intact lens capsule is a semi permeable membrane shown to be impermeable to large protein. This permeability pattern is altered in cataract (Patterson and Bunting, 1965). Increase in protein concentration by captopril and SPCM $(0.2 \mathrm{mg} / \mathrm{ml})$ implies that they mitigated protein damages; which is an important factor for maintaining or restoring lens transparency. However, SPCM at the lower dose of $0.1 \mathrm{mg} / \mathrm{ml}$ was not significantly protective.

GSH is a major antioxidant in the lens known to be present at a very high concentration (Javadzadeh et al., 2009; Kisic et al., 2012; Hui-Ping et al., 2013). Its maintenance has been reported to be vital for lenticular transparency (Isai et al., 2009) as it scavenges damaging radicals and reduces lenticular proteins by means of its sulfhydryl groups thereby preventing cross-linking and aggregation (Isai et al., 2009; Javadzadeh et al., 2009; Rooban et al., 2009). Evaluation of the level of reduced glutathione in the present investigation showed a reduction to $24.44 \%$ of normal control value in the untreated cataract group. The reduction might be attributed to increased binding of GSH to oxidized lens proteins, scavenging of the excess ROS and change in some part of the system that governs GSH-GSSG interchange and formation. Similar decrease to $26.4 \%$ was observed by Lakshmi and Sharma, (2011) while Gupta et al. (2009) observed decrease to 40.5\% when 30\% galactose added to the diet was used as cataract inducer. Generally, decrease in the amount of glutathione content of cataractogenic lenses has been reported (Harding, 1970; Özmen et al., 2000; Head, 2001). In this study, SPCM restored the depleted glutathione in a dose related manner to $57.7 \%$ and $42.22 \%$ of the normal control value respectively. The activity was comparable to captopril treated cataract group which also restored (75.55\%) glutathione depletion.

Ocular tissue possesses enzymatic antioxidant defenses such as superoxide dismutase and catalase, capable of catalytic removal of free radicals and other reactive species (Hui-Ping et al., 2012; Yang et al., 2013). Significant decrease in superoxide dismutase and catalase activities of the untreated cataract group compared to the normal control group as observed in this present investigation was an indication of increased oxidative stress with subsequent utilization of these enzymes. This was in line with previous studies showing that reported decreased enzyme activity in cataractogenesis (Awasthi et al., 1996). Jyothi (2003) observed $43.40 \%$ and $36.61 \%$ reduction in superoxide dismutase and catalase activities respectively as against $50.49 \%$ and $25.51 \%$ obtained in this study. Captopril and Spathodea campanulata exudate at the higher concentration protected the lenses and elevated the activities of these enzymes with their relative activities comparable. However, at lower dosage of SPCM lens treatment, no significant difference was observed in enzyme activities which indicated that SPCM $(0.1 \mathrm{mg} / \mathrm{ml})$ possesses very little potential to protect the lens against cataractogenesis.

\section{Conclusion}

In conclusion, spathodea campanulata flower bud exudate contains bioactive molecules that possess anti-cataract activity and protected the wistar rat lenses from galactose induced cataractogenesis as evidenced by the morphological assessment of the lenses and evaluation of various biochemical parameters of the lens.

\section{References}

1. Akinmoladun, A.C.; Ibukun, E.O., Afor, E., Obuotor, E. M. and Farombi, E.O. (2007). Phytochemical constituent and antioxidant activity of extract from the leaves of Ocimum gratissimum. Scientific Research and Essay 2: 163-166.

2. Awasthi, S.; Srivatava, S.K., Piper J. T., Singhal, S. S., Chaubey, M. and Awasthi, Y. C. (1996). Curcumin protects against 4-hydroxy-2-trans-nonenal induced cataract formation in rat lenses. American Journal of Clinical Nutrition 64: 761-766. 
3. Babizhayeva, M. A.; Vishnyakovac, K. S. and Yegorov, Y. E. (2010). Telomere-dependent senescent phenotype of lens epithelial cells as a biological marker of aging and cataractogenesis: the role of oxidative stress intensity and specific mechanism of phospholipid hydroperoxide toxicity in lens and aqueous. Fundamental and Clinical Pharmacology PP 1-29.

4. Benzie, I.F.F. and Strain, J.J. (1999). Ferric reducing ability of plasma (FRAP) as a measure of antioxidant power: The FRAP assay. Analytical Biochemistry 239:70-76.

5. Brand-Williams, W.; Cuvelier, M. E. and Beset, C. (1995). Use of free radical method to evaluate antioxidant activity. Lebensmittel-Wissenschaft und-Technologie/Food Science and Technology 28: 25-30.

6. Bukhari, S.B.; Bhanger, M.I. and Memon, S. (2008). Antioxidative Activity of Extracts from Fenugreek Seeds (Trigonella foenum-graecum). Pakistan Journal of Analytical and Environmental Chemistry 9: 78-83.

7. Duganath, N.; Reddy, K.N., Nagasowjanya, J., Sridhar, Sushma, and Jayaveera, K.N. (2010). Evaluation of phytochemical and in-vitro antioxidant activity of Filicium decipiens, Annals of Biological Research 1: 134-140.

8. Eman, M.A and Elabrak, E. S. (2011). Lens Protein Changes Associated With Cigarette Smoking. Life Science Journal 8: 553-558.

9. Gulcin I.; Sat G.I., Beydemirs, E. M. and Kfrevioglu O.I (2003). Comparism of antioxidant activity of Clove (Eugenia caryophylata Thumb) buds and lavender (Lavander stoechas L.). Food chemistry 87, 393-400.

10. Gupta, S. K.; Kalaiselvan, V., Srivastava, S., Saxena, R. and Agrawal, S. S. (2009). Inhibitory Effect of Trigonella Foenum-Graecum on Galactose Induced Cataracts in a Rat Model; in vitro and in vivo Studies. Journal of Ophthalmic and Vision Research 4: 213-219.

11. Harding, J. J. (1970). Free and Protein-Bound Glutathione in Normal and Cataractous Human Lenses. Biochemical Journal 117: $957-960$.

12. Hareesh, A. R.; kowti, R., Harsha, R., Ahmed, M.G., Kumar, S.B.P., Dinesha, R., Mohammed, I.A. and Gowda, T.S.S. (2010). In vitro Antioxidant and Free Radicals Scavenging Activity of Flower of Spathodea campanulata P. Beauv. International Journal of Pharmaceutical Science 2: 508-514.

13. Head, K.N.D. (2001). Natural Therapies for ocular disorders: Cataracts and Glaucoma. Alternative Medicine Review 6: 141-166.

14. Hsu, D. and Zimmer, V. (2010). Review: Advanced Glycation End-products in Diabetes Management. Canadian Journal of Diabetes 34: 136-140.

15. Hui-Ping, Q.; Shu-Qin, W., Xiang-Chun, G., Zhang, L.; Gao, X.; Nan-Nan, Y., Sheng, B. and Hao, C. (2013). Preventive effect of danshensu on selenite-induced cataractogenesis in cultured rat lens. Clinical and Experimental Ophthalmology 41: 172-179.

16. Hui-Ping, Q.; Shu-Qin, W., Xiang-Chun, G., Nan-Nan, Y., Wan-Zhen, H., Sheng, B. and Hao, C. (2012). Ursodeoxycholic acid prevents seleniteinduced oxidative stress and alleviates cataract formation: In vitro and in vivo studies. Molecular Vision 18:151-160.

17. Ilodigwe, E.E.; Akah, P.A. and Nworu, C.S. (2010). Anticonvulsant Activity of Ethanol Leaf Extract of Spathodea campanulata P. Beauv (Bignoniaceae). Journal of Medicinal Food 13: 827-833.

18. Isai, M.; Sakthivel, M., Ramesh, E., Thomas, P.A. and Geraldine, P. (2009). Prevention of selenite-induced cataractogenesis by rutin in Wistar Rats. Molecular Vision 15:2570-2577.

19. Javadzadeh, A.; Ghorbanihaghjo, A., Arami, S., Rashtchizadeh, N., Mesgari, M., Rafeey, M. and Omidi, Y. (2009). Prevention of Selenite-Induced Cataractogenesis in Wistar Albino Rats by Aqueous Extract of Garlic. Journal of Ocular Pharmacology and Therapeutics 25: 395-399.

20. Jobling, A. I. and Augusteyn, R. C. (2002). What causes steroid cataracts? A review of steroid induced posterior subcapsular cataracts. Clinical and Experimental Optometry 85: 61-75.

21. Jyothi, M.; Sanil, R., Sreekumar R. and Shashidhar S. (2003). Antioxidant Enzymes and Peroxidation in Galactogenic Cataract. Indian Journal of Physiology and Pharmacology 47: 197-201.

22. Killedar, S.G.; Kope, K.I., Sangle, S.B. and Tamboli, M.S. (2011). Standardization and Antimicrobial Activity of Watery Fluid at Floral Base of Spathodea campanulata (Pal). Asian Journal of Pharmaceutical Analysis 1: 19-21.

23. Kinoshita, J. H. (1965). Cataracts in galactosemia: The Jonas S. Friedenwald Memorial Lecture. Investigative Ophthalmology 4: 786-799.

24. Kinoshita, J. H. (1974). Mechanisms initiating cataract formation. Investigative Ophthalmology 13: 713-724.

25. Kisic, B.; Miric, D., Zoric L. and Ilic, A. (2012). Role of Lipid Peroxidation in the Pathogenesis of Age-Related Cataract. http://www.intechopen.com/books/lipid-peroxidation/role-of-lipid-peroxidation-in-the-pathogenesis-of-age-related-cataract. PP 457-482.

26. Kowti, R.; Harsha, R., Ahmed, M.G., Hareesh, A.R., Gowda, T.S.S., Dinesha, R., Kumar, S. and Ali, M. (2010). Antimicrobial activity of ethanol extract of leaf and flower of Spathodea campanulata P. Beauv. Research Journal of Pharmaceutical, Biological and Chemical Sciences 1: 691-698.

27. Kyselova, Z.; Stefe, k. M., and Bauer, V. (2004). Pharmacological prevention of diabetic cataract, Review. Journal of Diabetes and Its Complications 18: $129-140$.

28. Lakshmi, K.S.; Sharma, S., Rajesh, T. and Chitra, V. (2009). Captopril ameliorates Sodium Selenite induced Cataractogenesis in Rats: An In vitro and In vivo Study. Pharmacologyonline 2: 1205-1215.

29. Lakshmi, K. S. and Sharma, S. (2011). Potential of Allylmercaptocaptopril as an anti-cataract Agent against Galactosemic Cataract in Rats: An in Vitro and in Vivo Studies. European Journal of General Medicine 8: 122-129.

30. Lowry, O. H.; N. J. Rosebrough, A.L. Farr and R. J. Randall, 1951. Protein measurement with the Folin-Phenol reagents. Journal of Biological Chemistry 193: 265-275.

31. Luthra, M. and Balasubramania, D. (1993). Nonenzymatic Glycation Alters Protein Structure and Stability: A Study of Two Eye Lens Crystallins. The Journal of Biological Chemistry 268; 18119-18127.

32. Lyons, T.J.; Silvestri, G., Dunn, V., Dyer, D.G. and Baynes, J.W. (1991). Role of Glycation in Modification of Lens Crystallins in Diabetic and Nondiabetic Senile Cataract. Diabetes 40: 1010-1015.

33. Malone, J. I.; Benforda, S. A. and Malone, J. (1993). Taurine prevents galactose-induced cataracts. Journal of Diabetes and its Complications 7: 4448.

34. Marcantonio, J. M. and Vrensen G. (1999). Cell biology of posterior capsular opacification. Eye 13: 484-488.

35. Marsili, S.; Rudolf, I., Salganikb, C., Albrightb, C. D., Freela, C. D., Johnsend, S., Peiffere R. L. and Costello, M. J. (2004). Cataract formation in a strain of rats selected for high oxidative stress. Experimental Eye Research 79: 595-612.

36. Miliauskas, G.; Venskutonis, P.R. and Van Beek, T. A. (2004). Screening of radical scavenging activity of some medicinal and aromatic plant extract. Food Chemistry 88: 231-237.

37. Misra, H.P. and Fridovich, I. (1972): The role of Superoxide Anion in the Autoxidation of Epinephrine and a Simple Assay for Superoxide Dismutase. Biochemical Journal 247: 3170-3175. 


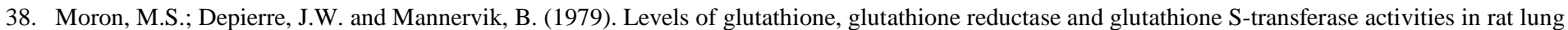
and liver. Biochemical and Biophysics Acta 582: 67-78.

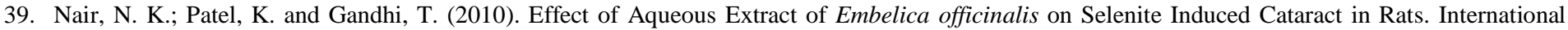
Journal of Production Research 9: 147-152.

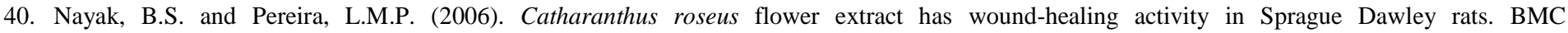
Complementary and Alternative Medicine 6: 41-46.

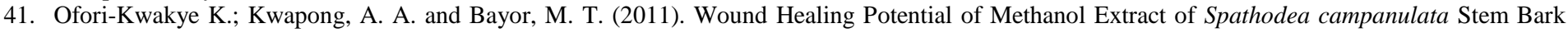
Formulated into a Topical Preparation. African Journal of Traditional Complementary and Alternative Medicine 8: 218-223.

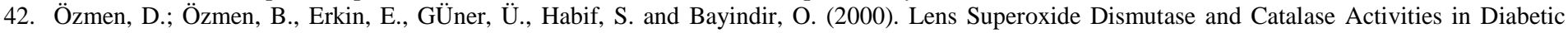
Cataract. Turkish Journal of Endocrinology and Metabolism 1: 1-4.

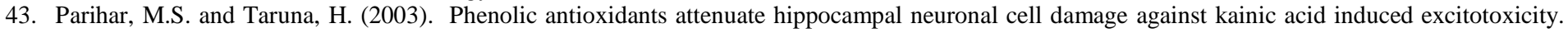
Journal of Biological Science 28: 121-128.

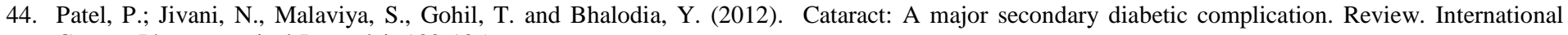
Current Pharmaceutical Journal 1: 180-185.

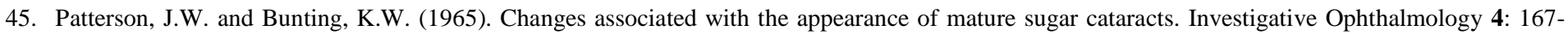
173.

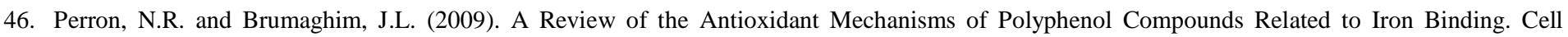
Biochemistry and Biophysics 53: 75-100.

47. Pintor, J. (2012a). Sugars, the Crystalline Lens and the Development of Cataracts. Biochemical Pharmacology 1: 1-3.

48. Pintor, J. (2012b). Why do cataracts appear in cases of diabetes or galactosemia? (Review). Journal of Emmetropia. 4: $209-212$.

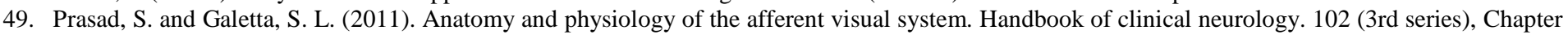
1.

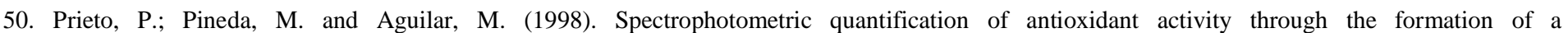
phosphomolybdenum complex: Specific application to the determination of vitamin E. Analytical Biochemistry 269: 337-341.

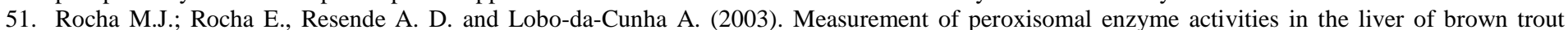
(Salmo trutta), using spectrophotometric methods. BioMedCentral Biochemistry 4: 1-9.

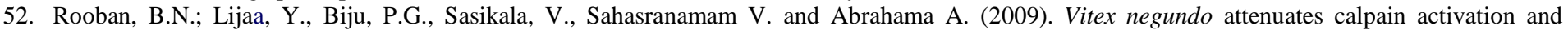
cataractogenesis in selenite models. Experimental Eye Research 88: 575-582.

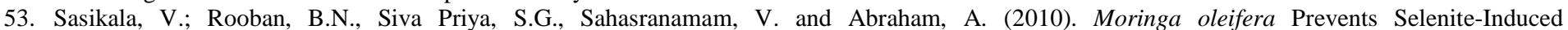
Cataractogenesis in Rat Pups. Journal of Ocular Pharmacology and Therapeutics 26: 441-447.

54. Segree, L. (2014). Human Eye Anatomy: Parts of the Eye. www.allaboutvision.com/resources/anatomy.htm

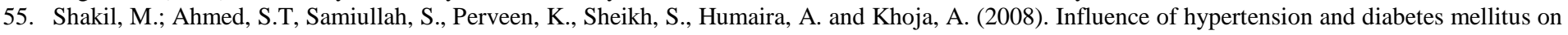
senile cataract. Pakistan Journal of Physiology 4: 30-32.

56. Shichi, H. (2004) Cataract formation and prevention. Expert Opinion on Investigational Drugs 13: 691-701.

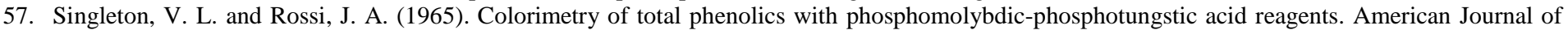
Enol and Viticulture. 16:144-158.

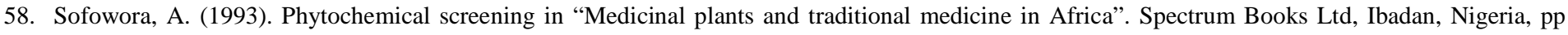
$150-172$.

59. Spector A. (1995). Oxidative stress induced cataract: Mechanism of action. Federation of American Societies for Experimental Biology 9: $1173-1182$.

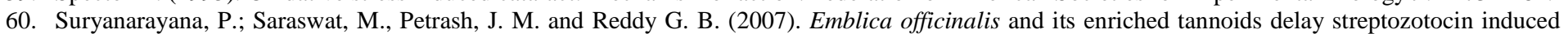
diabetic cataract in rats. Molecular Vision 13: 1291-1297

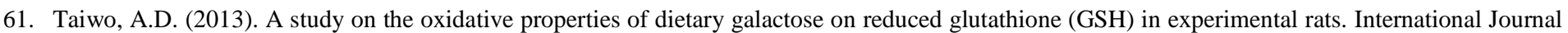
Educational Research and Reviews 1: 019-022.

62. Trease, E. and Evans, W.C. (2002). Pharmacognosy. 15th Edition, Sunders Publishers. Pp 229-246.

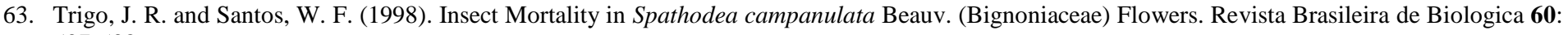
537-538.

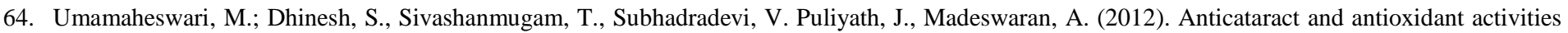
of Achyranthes aspera Linn. against glucose-induced cataractogenesis using goat lenses. Journal of Natural Product and Plant Resources 2: 153-161.

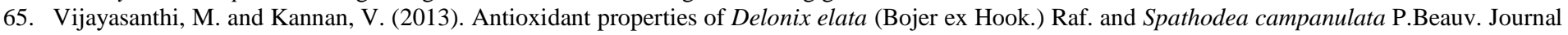
of Medicinal Plants 2: 94-98.

66. Williams, D.L. (2006). Oxidation, antioxidants and cataract formation: a literature review. Veterinary Ophthalmology 9: $292-298$.

67. Yang, C.; Yan, H., and Ding T. (2013). Hydrogen saline prevents selenite-induced cataract in rats. Molecular Vision 19:1684-1693.

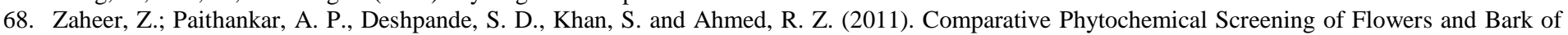
Spathodea campanulata. International Journal of Applied Biology and Pharmaceutical Technology 2: 233-235.

69. Zarina, S.; Abbasi, A. and Zaidi, Z.H. (1994). Cataractous lens and its environment. Pure and Applied Chemistry 66: 111-115. 